2. Rudel, R., Lehmann Horn, F., Ricker, K. \& Kuther, G. Hypokalaemic periodic paralysis: in vitro investigation of muscle fibre membrane parameters. Muscle Nerve 1984, 7: 110-120.

3. Lipicky, R.J., Bryant, S.H. \& Salmon, J.H. Cable parameters, sodium, potassium, chloride and water content, and potassium efflux in isolated external intercostal muscle of normal volunteers and patients with myotonia congenita. J Clin Invest 1971, 50: 2091.

4. Griggs, R.C. \& Ptacek, L.J. The periodic paralysis. Hosp Pract 1992, 27: 123-127.

5. Fordeau, M. \& Tome, F.M.S. Childhood myopathies. In: Swash, M. \& Oxybury, J. (eds) Clinical Neurology. Churchill Livingstone, Edinburgh, 1991, pp. 1266-1286.

6. Leyburn, P. \& Walton, J.N. The effect of changes in serum potassium upon myotonia. J Neurol Neurosurg Psychiatry 1960, 29: $1131-1137$.

7. Resnick, J.S. \& Engel, W.K. Myotonic lid lag in hypokalaemic periodic paralysis. $J$ Neurol Neurosurg Psychiatry 1967, 30: 47-51.

\section{Anatomy-tragic or comic muse?}

Sir,

\section{Introduction}

There is one matter about which medical students and their loved and loving teachers are of a single mind: anatomy courses (sometimes paradoxically described as the teaching of human anatomy) have but one purpose-to generate inconsolable weeping. Our present investigation, which has been conducted under the influence of acres humores, is devoted to clarifying the hitherto unexplained pathogenesis of this phenonemon.

\section{Materials and methods}

As with all anatomical research, this inquiry has been carried out with a precision which would make Occam's razor look like a blunted butter knife. The author sat for 9 and 30 years under the most eminent professors in the greatest universities in the world in order to establish the incontrovertible truth of his observations. At no time was the objectivity of his investigation sullied by the slightest hint of vulgar personal academic success. The flowers culled as a result of this devotion constitute the substance of the present communication, or-to put it more crudely-the results.

\section{Results}

\section{Introduction to the subject}

Anatomy is beyond all discussion by far the most important science in the medical curriculum: doctors lacking anatomy are like moles; they toil in the dark and the fruits of their labours are-mounds of earth!

\section{Single examples concerned with regional anatomy}

The head can be subdivided into two main regions: the neurocranium, which contains the brain, and the viscerocranium, housing the upper end of the alimentary canal.
Translated into the student vernacular these become 'think-box' and 'nosh-hole'.

The classical work on the soft tissue coverings of the cranium was completed in North America before the turn of the century. Five layers are recognized: S (skin), C (connective tissues), A (aponeurosis), L (loose connective tissue) and P (periosteum).

A large portion of the gut is said to be intraperitoneal. That does not imply that, when the abdominal cavity is laid open, the uncovered gut is immediately extruded. Never forget that: in general, nothing is to be found within the peritoneal cavity except a thin film of fluid (less commonly, a pair of surgical scissors; only rarely, an undersized theatre nurse).

Amongst a host of other bony excrescences, the pelvis possesses a pubic tubercle. Is it possible that Sigmund Freud was inspired to write 'The Psychopathology of Everyday Life' after hearing one of his students refer to it as the 'public tubercle'?

The vagina lies between the urethra and rectum. It therefore cannot be gainsaid that: we come into the world between urine and faeces (an observation that has been immortalized with greater lyricism by at least one renowned poet. In a less respectable journal than this it could be expressed even more succinctly).

Unlike that of the foot, the dorsum of the hand contains no fleshy muscular tissue. The following recommendation is self-explanatory: a cannibal who buys a cut from the back of the hand must starve. He should have bought a sirloin of foot.

The tendons of three muscles pass behind the medial malleolus, but the fleshy belly of only one of them reaches the ankle region. Thus: the beef in the heel (N.B. the author is not, unfortunately, sponsored by McDonalds).

\section{On professors of anatomy}

During a viva the candidate showed himself unable to identify the various regions of the alimentary canal: 'And how', the examiner inquired, 'do you expect to become a doctor without carrying the gut in your head?'

One possible way, among many, of bringing an anatomy lecture to a satisfactory conclusion: A good lecture is like a miniskirt: short enough to arouse interest, but long enough to hide all the essentials.

\section{Conclusions}

Our conclusion is as startling as it is irrefutable: the floods of tears would seem to be those of pleasure, joy and laughter. The anatomist is, it appears, a hedonist!

\section{Acknowledgement}

The author wishes to express his gratitude to Dr F. and J. Steel, M.A., for translating the manuscript. ${ }^{1}$

J.H.D. Fasel

Department of Morphology, Centre Médical Universitaire, 1 Rue Michel-Servet, CH-1211 Geneva 4, Switzerland.

\section{Reference}

1. Fasel, J.H.D. Anatomie-einmal ganz anders (Anatomy-An Unusual Point of View). Satyr Editions, Zurich, 1993. 